\title{
JOHN SHAW BILLINGS, FLORENGE NIGHTINGALE AND THE JOHNS HOPKINS HOSPITAL
}

IN Kelly and Burrage's American Medical Biography (1920) it is stated that Billings was 'among the five men who, in 1876 , were invited by the Board of the Johns Hopkins Hospital Foundation to submit plans for the new hospital, and his plan was selected as the best one'. It is not generally known that Billings, in his endeavours to perfect the plans for the hospital, travelled on the continent of Europe and visited England, where he consulted Miss Florence Nightingale. Among the Nightingale manuscripts at the British Museum the following two letters from Dr. Billings to Miss Nightingale are included. They sufficiently explain why they were written and indicate the response the first letter obtained from Miss Nightingale.

The first letter is dated 23 October 1876 and runs as follows:

I take the liberty of sending to you through Mrs Wardroper, who has very kindly consented to forward the package, a set of sketch plans for a hospital to be constructed at Baltimore, U.S. under the terms of the Johns Hopkins Trust. With this hospital are to be connected a training school for nurses, a convalescent hospital, an orphan asylum and some other things. I am now on my way to the Continent and shall return towards the end of November, spending a day or two in London on my way to the U.S.

Knowing as I do the great interest you take in such subjects I shall consider it as a great favour if before my return you will, if your health permits, examine these plans and the two pamphlets which accompany them and let me know what you think of them. They are only sketch plans and I desire criticism before going further. I am with great respect

very sincerely yours

John S. Billings

The second letter is dated 4 December 1876 and shows to what good purpose Miss Nightingale examined the plans.

I have the honour to acknowledge the receipt of your letter of Dec. 2. enclosing 12 sheets of notes on the Johns Hopkins Hospital plans, and I desire to express my sincere personal thanks for this favour. Your remarks shall be laid before the Trustees as soon as I return to America and I feel sure that they will be greatly interested in and influenced by your criticisms.

The labour and expense of conducting an hospital built in this general plan I fully appreciate as also the complications which arise in trying to cut off all service rooms from the ward. I infer from your note that you may not have received a copy of a book containing five different plans for this hospital published by the Trustees about 9 months ago. I am quite sure that a copy was sent to you. The first of the plans in that book I prepared and in it I think many of your objections were avoided. If you have not seen it I shall make sure that a copy is sent to you. 


\section{News, Notes and Queries}

That at first but one or two blocks should be built is precisely what I think. But I will not attempt now to comment upon your notes nor indeed do I think it probable that I should do otherwise than agree with them. The copies of plans sent you were intended to be kept by you and other plans will be sent to you hereafter. If you have not the volume containing the five plans and will let me know it I will have it sent. For the next 9 days my address will be care of Brown Shipley and Co, Founders Court, Lothbury, London. After that Surgeon Generals Office, Washington D.C. U.S.A. I leave London by the $5^{\text {th }}$ inst for Leeds, Edinburgh etc and sail on the 16 th. Again thanking you for your criticism.

very respectfully and truly yours

Miss Florence Nightingale

John S. Billings, M.D. U.S.A.

ZAGHARY COPE 